\title{
Retinal Pigment Epithelial Detachment in Age-Related Macular Degeneration
}

\author{
Michael Karampelas (D) Panagiotis Malamos - Petros Petrou • \\ Ilias Georgalas · Dimitrios Papaconstantinou • Dimitrios Brouzas
}

Received: July 9, 2020 / Published online: August 18, 2020

(C) The Author(s) 2020

\section{ABSTRACT}

Retinal pigment epithelial detachment is defined as a separation of the retinal pigment epithelium from the inner collagenous layer of Bruch's membrane. It is a common manifestation in both dry and wet types of age-related macular degeneration. This review aims to provide a comprehensive guide to the pathophysiology, clinical and imaging characteristics, natural course and treatment of the various types of pigment epithelial detachments in order to assist in diagnosis and management of this important feature of age-related macular degeneration.

Digital Features To view digital features for this article go to https://doi.org/10.6084/m9.figshare.12765821.

M. Karampelas $(\bowtie)$

Ophthalmology Department, Hippokration General Hospital, Athens, Greece

e-mail: mikekarampelas@hotmail.com

P. Malamos

Imaging of the Fundus and Macula, Athens, Greece

P. Petrou · I. Georgalas · D. Papaconstantinou .

D. Brouzas

First Division of Ophthalmology, School of

Medicine, National and Kapodistrian University of

Athens, "G. Gennimatas" General Hospital, Athens,

Greece
Keywords: Age-related macular degeneration; Drusenoid; Fibrovascular; Haemorrhagic; Pigment epithelial detachment; Serous

\section{Key Summary Points}

Retinal pigment epithelial detachment (PED) is a common manifestation in both dry and wet types of age-related macular degeneration (AMD).

PEDs often result in loss of vision by either atrophy or choroidal neovascularization.

Multimodal imaging is essential for the correct recognition of their various types and appropriate patient counselling and management.

Intravitreal anti-VEGF therapy is an effective treatment in the majority of eyes with fibrovascular PEDs and similar visual outcomes have been reported with different treatment regimens.

\section{INTRODUCTION}

Retinal pigment epithelial detachment (PED) is defined as a separation of the retinal pigment epithelium (RPE) from the inner collagenous 
layer of Bruch's membrane. It was first described by Gass in 1966 [1] as a serous elevation of the RPE. Gass subsequently performed a study on 200 eyes with age-related macular degeneration (AMD) and reported serous as well as fibrovascular and haemorrhagic PEDs that had a negative visual effect [2]. In 1985, Bird described drusenoid PEDs as a third type of PED related to AMD [3].

PEDs represent a common manifestation in AMD [including idiopathic polypoidal choroidal vasculopathy (IPCV)] and develop in more than $80 \%$ of eyes with wet AMD [4-8]. Recent advances in ophthalmic imaging have further enhanced our understanding of the various types of PEDs in AMD and have given us great insight in their pathophysiology, natural course and treatment response.

The present review aims to provide a comprehensive guide in order to assist in the diagnosis and management of this important feature of AMD. This article is based on previously conducted studies and does not contain any studies with human participants or animals performed by any of the authors.

\section{PATHOPHYSIOLOGY}

The pathophysiology of AMD involves an intricate network of complex interactions between metabolic, functional, genetic and environmental factors. One of the main targets of these processes is the RPE-Bruch's membrane complex. Ageing results in structural changes in both RPE and Bruch's membrane, including loss of melanin granules, accumulation of residual bodies, calcification and fragmentation [9-15]. A linear relationship between ageing and thickening of Bruch's membrane has been established by both microscopy and optical coherence tomography (OCT) $[12,13,16]$.

The formation of PEDs in the context of AMD involves the following mechanisms:

(a) Progressive deposition of materials and thickening of Bruch's membrane with age, resulting in a gradual decrease in hydraulic conductivity that leads to impermeability to the passage of fluid $[3,4,17]$. (b) Progressive accumulation of residual bodies in RPE cells, leading to the formation of drusen with gradual separation of the RPE from Bruch's membrane [2, 18, 19].

(c) Formation of choroidal neovascularization (CNV) leading to the ingrowth of leaking vessels in the sub-RPE space through Bruch's membrane $[20,21]$.

In AMD, three main types of PED are observed: serous, drusenoid and fibrovascular/ haemorrhagic.

\section{Pathophysiology of Serous PEDs}

The pathogenesis of serous PEDs in AMD is related to a spectrum of different mechanisms ranging from degenerative changes in Bruch's membrane to the formation of $\mathrm{CNV}$. It was originally thought that the detachment of the RPE was caused by the passage of fluid from the choriocapillaris and through Bruch's membrane [22], but this was not supported by evidence. In 1986, Bird and Marshall introduced the concept of reduced hydroconductivity at the level of Bruch's membrane as a result of ageing [5]. In 1987, Fisher et al. reported a gradual decrease in the hydraulic conductivity of Bruch's membrane [23], and this was confirmed by subsequent studies [17, 24]. A linear relationship between the thickness of Bruch's membrane and age was found, ranging from $2 \mu \mathrm{m}$ in the first decade to $4.7 \mu \mathrm{m}$ in the tenth decade [13]. The increased thickness as well as the gradual deposition of lipid material are thought to be the main causes of the reduced conductivity in Bruch's membrane. This gradual hydrophobicity of Bruch's membrane creates a barrier to the normal passage of fluid towards the choriocapillaris by the RPE's ion pumps, causing the physical separation of RPE.

In addition, despite the fact that $\mathrm{CNV}$ is not a universal finding in serous PED, its presence provides an alternative source for the sub-RPE fluid. 


\section{Pathophysiology of Drusenoid PEDs}

The formation of drusenoid PEDs in the context of AMD is related to the gradual deposition of materials in the RPE-Bruch's membrane complex. Drusenoid PEDs are thought to be the product of a gradual enlargement and coalescence of pre-existing soft drusen $[3,19,25]$. The deposits reduce the hydraulic conductivity of Bruch's membrane and also interfere with the RPE pump. This process plays a significant role in the progression of hard to soft drusen as well as the gradual coalescence of soft drusen to form a drusenoid PED [4].

There is no established criterion to differentiate large drusen from drusenoid PEDs, but the Age-Related Eye Disease Study defined a large druse as measuring more than $125 \mu \mathrm{m}$ and a drusenoid PED as measuring more than $350 \mu \mathrm{m}$ [26].

\section{Pathophysiology of Fibrovascular/ Haemorrhagic PEDs}

Fibrovascular PEDs indicate the presence of $\mathrm{CNV}$ [27]. The abnormal new vessels emanating from the choroid gain entrance to the sub-RPE space through breaks in Bruch's membrane. The new vessels usually proliferate laterally between the RPE and Bruch's membrane and subsequently develop an organized vascular network $[28,29]$. These abnormal vessels lack a proper inner blood-retina barrier and therefore tend to leak and bleed, thus playing a central role in the formation of this type of PED [20]. IPCV, which is considered a variant of $A M D$, is characterized by multiple recurrent, often haemorrhagic PEDs caused by leakage and bleeding of sub-RPE aneurysmal polyps [7].

\section{CLINICAL AND IMAGING CHARACTERISTICS}

\section{Serous PEDs}

Serous PEDs appear as dome-shaped elevations of the RPE with sharp borders [1]. On fundoscopy, they may have a translucent or an orange-yellowish appearance. On fluorescein angiography (FA), they exhibit early hyperfluorescence within a well-defined space and gradual pooling with no leakage [30]. The presence of a hyperfluorescent notch at the edge of the PED is a strong sign of the presence of CNV $[20,31]$. In these cases, indocyanine angiography (ICGA) is a very useful tool for differentiation of a vascularized from a non-vascularized PED. A serous PED is typically seen as an area of hypofluorescence on ICGA, and this is more pronounced on modern confocal scanning laser ophthalmoscopy (SLO) systems [32] (Fig. 1). In contrast, a vascularized PED will have a hyperfluorescent notch or plaque associated with the CNV [32]. On fundus autofluorescence (FAF), serous PEDs most commonly appear as an area of hyper-autofluorescence that may be surrounded by a hypo-autofluorescent border [33]. In some cases, other FAF patterns have been observed, including hypo-autofluorescence or radial hyper-autofluorescent lines. These findings are mostly related to the presence of RPE hyperplasia [34].

On OCT, a serous PED will appear as a domeshaped elevation of the RPE over a hypo-reflective space, with Bruch's membrane being commonly visible as a straight, thin hyper-reflective line at the base of the elevation [27] (Fig. 2). The presence of intraretinal (IRF)/subretinal fluid (SRF) or hyper-reflective structures within the PED imply the presence of CNV.

However, a shallow retinal detachment at the apex or the borders of a very steep serous PED is not always associated with CNV, and alternatively could be attributed to mechanical stress and retinal "tenting".

\section{Drusenoid PEDs}

Drusenoid PEDs appear as well-circumscribed yellow-white elevations of the RPE that are usually within the posterior pole. Their borders are usually scalloped and they may have an irregular surface with areas of hyperpigmentation [35]. On FA, they usually exhibit early mild hyperfluorescence with late staining without any leakage (Fig. 3). Focal hyper- and hypofluorescence may be seen corresponding to areas of 


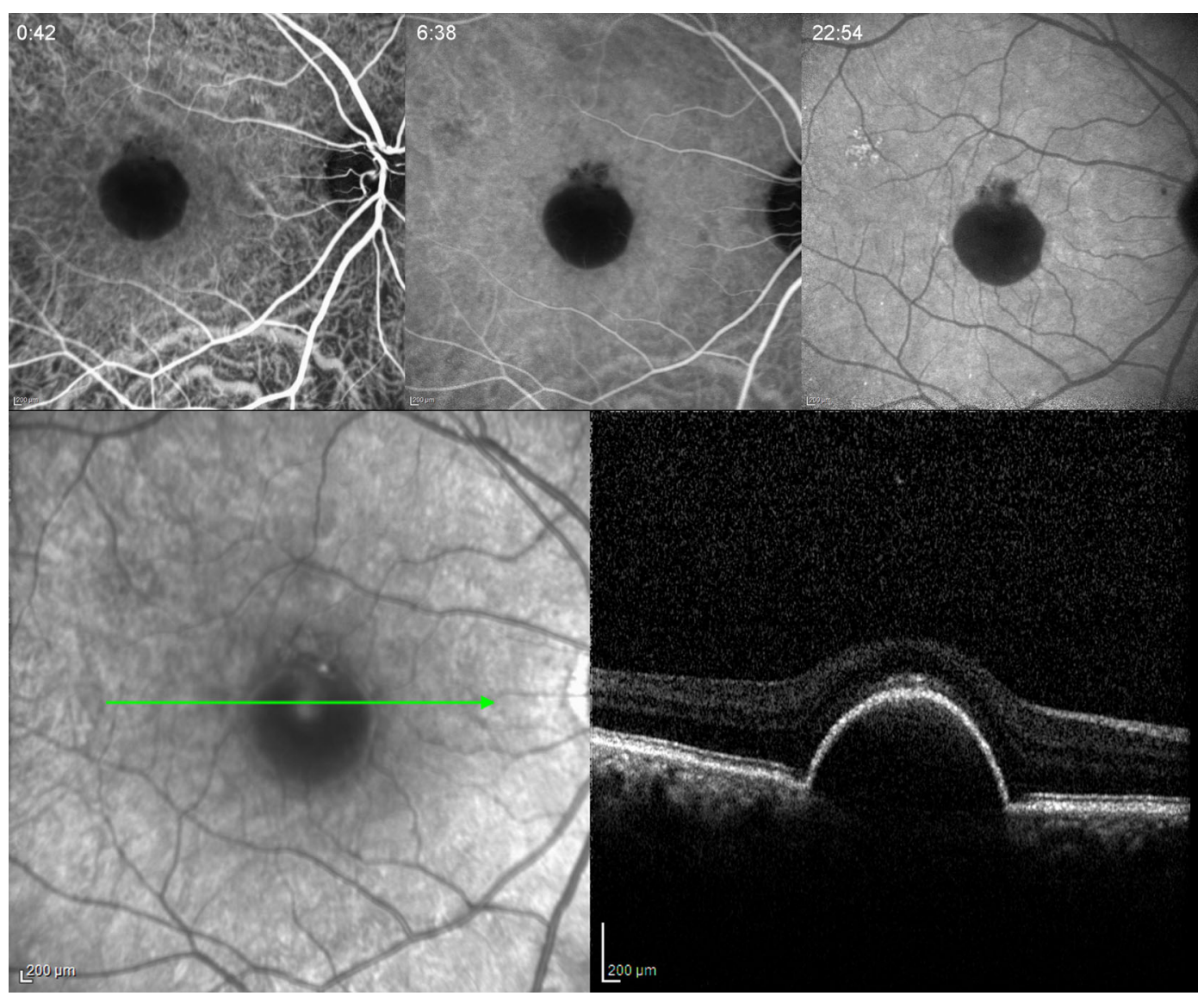

Fig. 1 Serous PED in a 58-year-old woman. Early, mid- and late phase of ICGA showing hypofluorescence in all phases. Note the absence of a hot spot. Spectral-domain OCT (SD-OCT) did not demonstrate any IRF or SRF

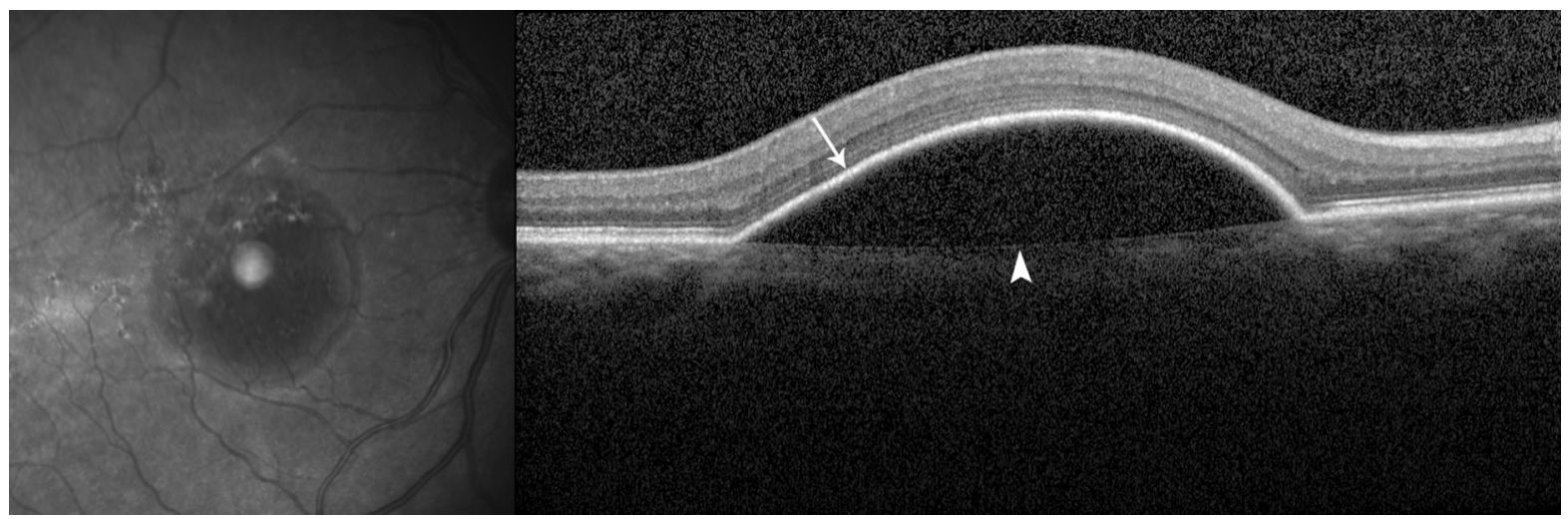

Fig. 2 SD-OCT of a serous PED. The PED appears as a dome-shaped elevation of the RPE (arrow) over a uniform hyporeflective space. Bruch's membrane is seen at the base of the PED (arrowhead)

atrophy or hyperpigmentation, respectively [35]. On ICGA, a drusenoid PED will appear as a smooth iso- or hypofluorescent area, the latter most commonly seen with modern confocal SLO systems [36, 37]. On FAF, they typically appear as hyperfluorescent or isofluorescent 


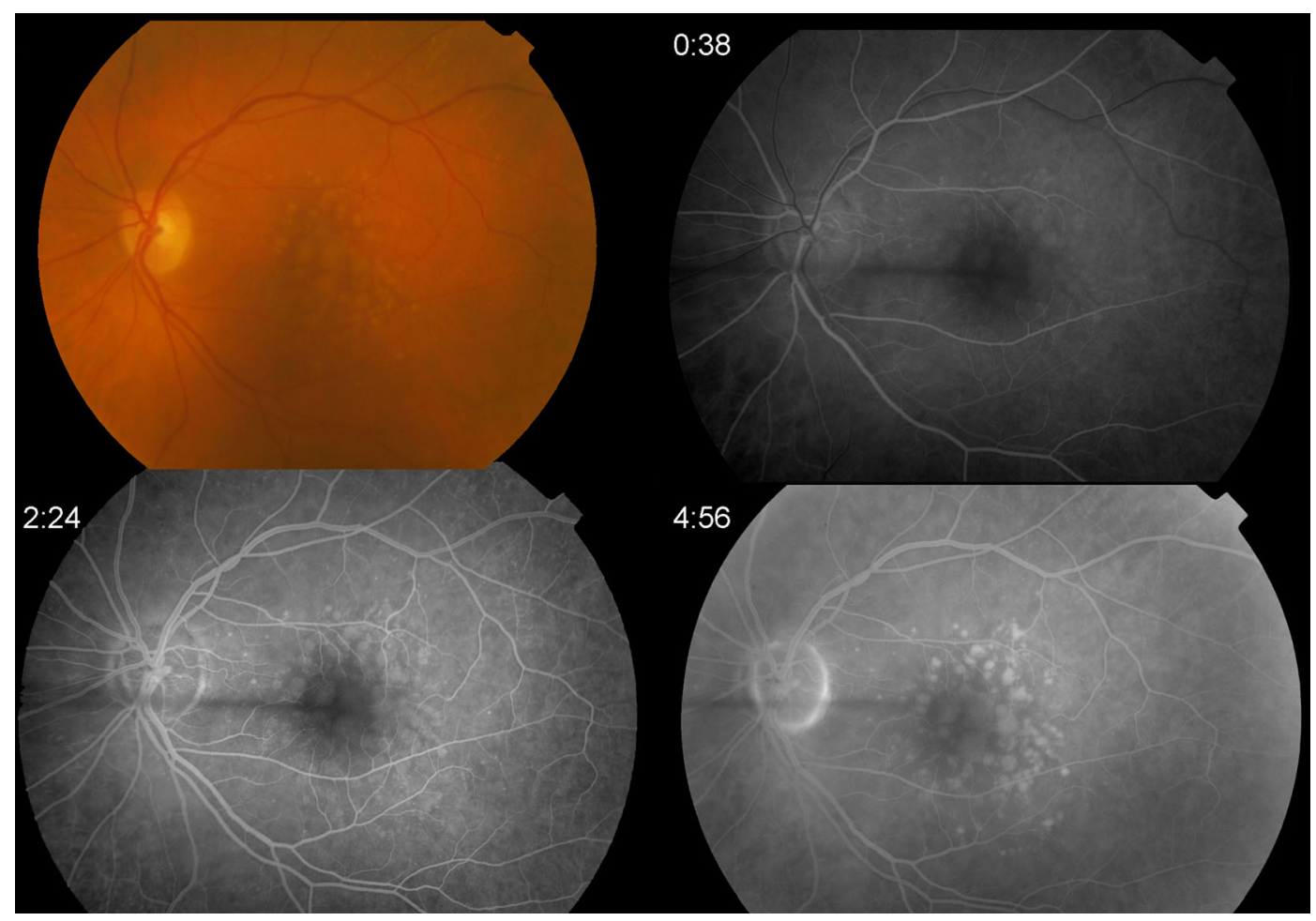

Fig. 3 Drusenoid PED in a 76-year-old woman. Color fundus photograph with multiple soft drusen, RPE changes and a central drusenoid PED. Early, mid- and late phase of

areas [38]. They often have a hypo-autofluorescent halo as well as focal areas of increased autofluorescence that correspond to areas of RPE clumping [33]. On OCT, drusenoid PEDs appear as RPE elevations over homogeneous mildly hyper-reflective spaces. Bruch's membrane is often seen at their base. In cases where significant heterogeneous optical reflectivity is seen within the PED and/or with the presence of IRF/SRF, CNV should be suspected. In some cases, the presence of a small hypo-reflective area adjacent to the PED that does not change significantly with time might not be associated with $\mathrm{CNV}$ but might be related to retinal "tenting" [39] (Fig. 4).

\section{Fibrovascular/Haemorrhagic PEDs}

Fibrovascular PEDs, by definition, are related to the presence of CNV. The most common type of $\mathrm{CNV}$ seen in these cases is type 1 according to
FA showing early hyperfluorescence corresponding to the area of drusen and PED as well as late staining with no leakage

the original classification by Gass, which represents neovascular growth below the RPE [40]. Other types of CNV related to fibrovascular PEDs are type $3 \mathrm{CNV}$ [retinal angiomatous proliferation (RAP)] and IPCV.

On clinical examination, they appear as RPE elevations with irregular surface and often with mixed serous and haemorrhagic or fibrous parts. Other findings include subretinal or intraretinal exudates, haemorrhage, and IRF and SRF [20].

On FA, their typical appearance is that of stippled hyperfluorescence that begins 1-2 min after the injection of dye and exhibits late leakage and/or staining [41] (Fig. 5). This angiographic pattern corresponds to one of the two main types of "occult" CNV, the other being late leakage of an undetermined source [41]. In general, and in contrast to "classic" $\mathrm{CNV}$, the angiographic type of "occult" $\mathrm{CNV}$ does not demonstrate a clear identification of the neovascular membrane in the early phase of the angiogram due to its sub-RPE location and 

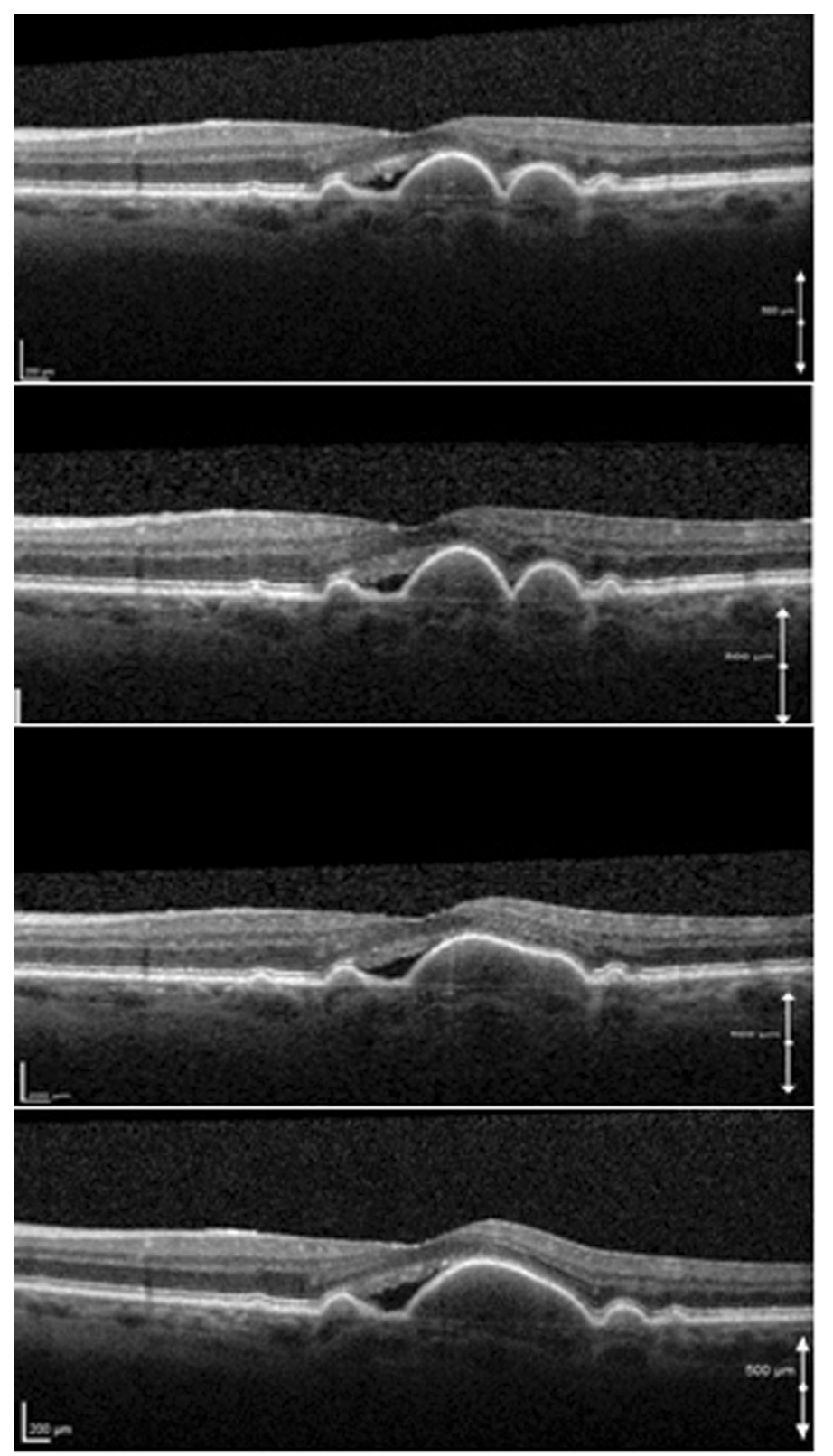

Fig. 4 Serial SD-OCT scans of a 68-year-old woman with soft drusen and an adjacent hypo-reflective space who was followed up for 3 years. OCT scans were taken on yearly intervals. Note the gradual coalescence of soft drusen and the development of a drusenoid PED. The PED has a

the presence of fibrin and blood. Hemorrhagic PEDs will show blockage through all phases. On ICGA, fibrovascular PEDs demonstrate either a focal well-defined hyperfluorescent area less than 1 disc diameter in size, which is referred to homogenous, mildly hyper-reflective interior, and Bruch's membrane is seen at its base. During the observation period the hypo-reflective space and visual acuity remained stable

as a hot spot, or a larger and variably delineated area of hyperfluorescence which is referred to as a plaque [32]. In the presence of IPCV, ICGA will reveal the polyps as well as the corresponding branching vascular network, which is 


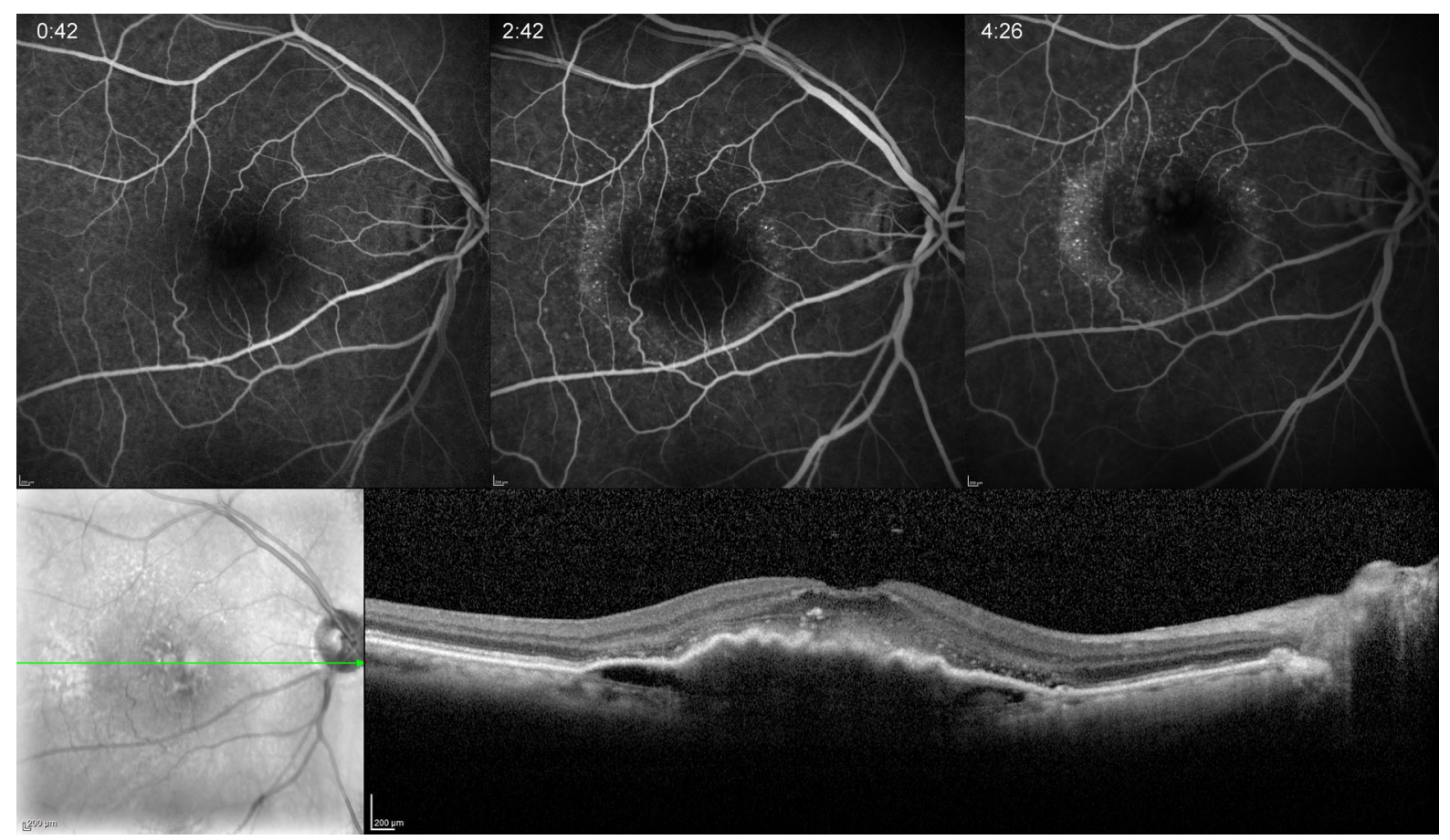

Fig. 5 Occult CNV in a 76-year-old woman. Early, midand late frames of FA demonstrating stippled hyperfluorescence in mid- and late phases. SD-OCT shows an irregular elevation of the RPE with a non-uniform hyper-

also easily delineated with OCT angiography (OCTA) (Fig. 6).

On FAF, fibrovascular PEDs exhibit a variety of patterns including areas of hyper- and hypoautofluorescence corresponding to RPE proliferation, photoreceptor loss, organized blood and atrophy, or masking by fresh blood [42, 43].

On OCT, and in contrast to serous PEDs, they usually appear as irregular elevations of the RPE with an interior that is not optically empty [27]. In contrast to drusenoid PEDs, they exhibit an optically non-uniform interior with hyperand hypo-reflective layers (Fig. 7). Enhanceddepth imaging-OCT as was described by Spaide, enables better visualization and can provide more information concerning the PED contents [44]. Other common OCT signs are the presence of IRF and SRF, and hyper-reflective areas from exudates and blood as well as RPE migration.

OCTA is a relatively new non-invasive modality that can significantly help in differentiating between vascular and avascular PEDs [45]. In fibrovascular PEDs, the presence of reflective interior. There is also mild SRF and hyperreflective foci in the neuroretina

abnormal flow on cross-sectional scans and the presence of an abnormal vascular complex on en-phase OCTA can be easily detected $[46,47]$ (Fig. 8).

A summary of clinical and imaging characteristics is displayed in Table 1.

\section{NATURAL COURSE AND TREATMENT OPTIONS}

\section{Serous PEDs}

Serous avascular PEDs are found in around 10\% of patients with AMD [48-50]. They do not usually constitute an immediate threat to vision, and due to the absence of $\mathrm{CNV}$ tend to have a more chronic and indolent course [6]. Previous studies have shown that in $32-39 \%$ of cases CNV will develop, in 21-38\% the PED will eventually flatten and become atrophic, and in $22 \%$ it will remain unchanged within an 


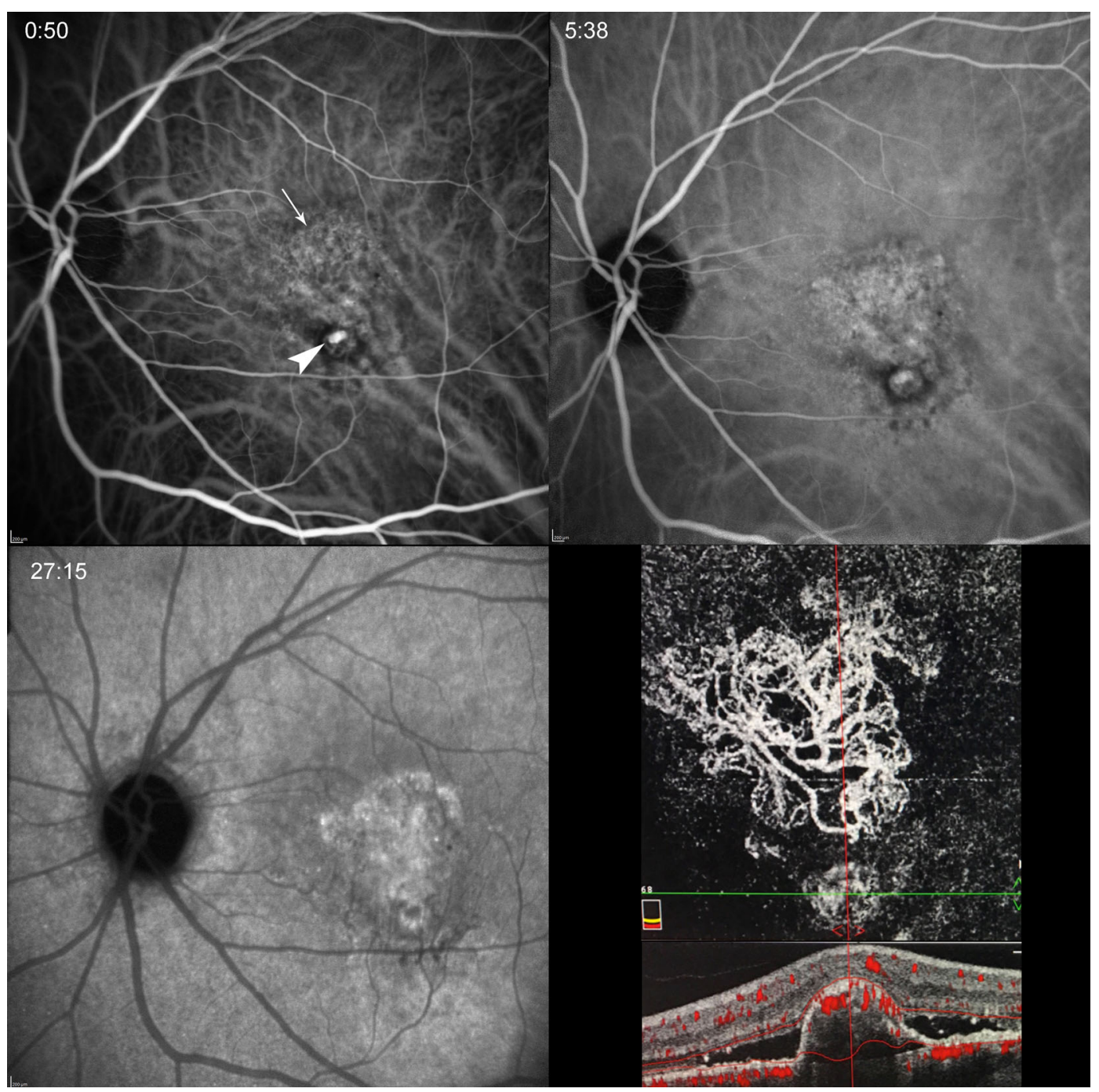

Fig. 6 IPCV in a 70-year-old man. Early, mid- and late phase of ICGA showing the polyp (arrowhead) as well as associated branching vascular network (arrow) that is more clearly delineated on en-phase OCTA (lower right panel).

average follow-up period of 19.6-27 months $[6,51,52]$.

Factors that increased the likelihood of CNV formation were older age, larger PED base diameter and history of $\mathrm{CNV}$ in the other eye $[6,51,52]$.

Currently, no treatments have been proven effective for serous avascular PEDs [53-55], and in clinical practice most cases are managed with regular follow-up and monitoring.
Cross-sectional OCTA demonstrates a steep, convex PED with non-uniform hyper-reflective interior, vascular flow at its apex and surrounding SRF

\section{Drusenoid PEDs}

Drusenoid PEDs are features of intermediate dry AMD and they occur in $8 \%$ of patients with AMD [26]. Their natural course was investigated in the prospective, multicenter, long-term AgeRelated Eye Disease Study [26]. Advanced AMD developed within 5 years in $42 \%$ of eyes, $19 \%$ progressing to center-involving geographic atrophy and $23 \%$ to CNV. In $40 \%$ of eyes there was a decrease in visual acuity (VA) by 15 or more letters at 5 years. Previous retrospectives 


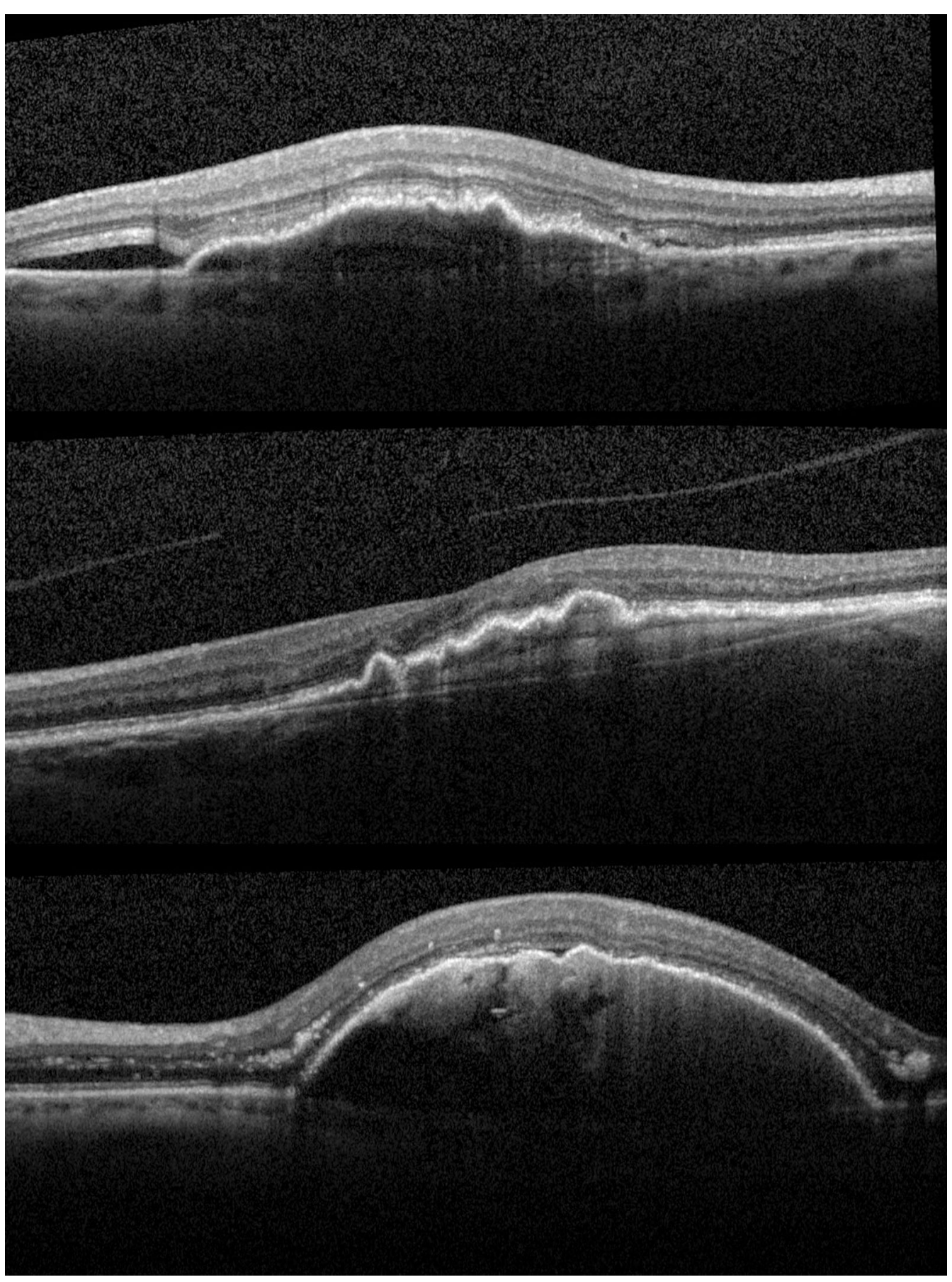

Fig. 7 SD-OCT scans of different cases of fibrovascular PEDs. Note the irregular elevation of the RPE, the inhomogeneous hyper-reflective interior, and the presence of SRF (top, bottom) as well as hyper-reflective neuroretinal foci (top, bottom)

studies have yielded similar findings: in 22-67\% of eyes the PED persisted or increased, in $49-65 \%$ of eyes there was progression to central geographic atrophy, and in $9-13 \%$ of eyes $\mathrm{CNV}$ occurred [3, 5, 56, 57].

Currently, there is no recommended treatment for drusenoid PEDs. Thermal laser has 


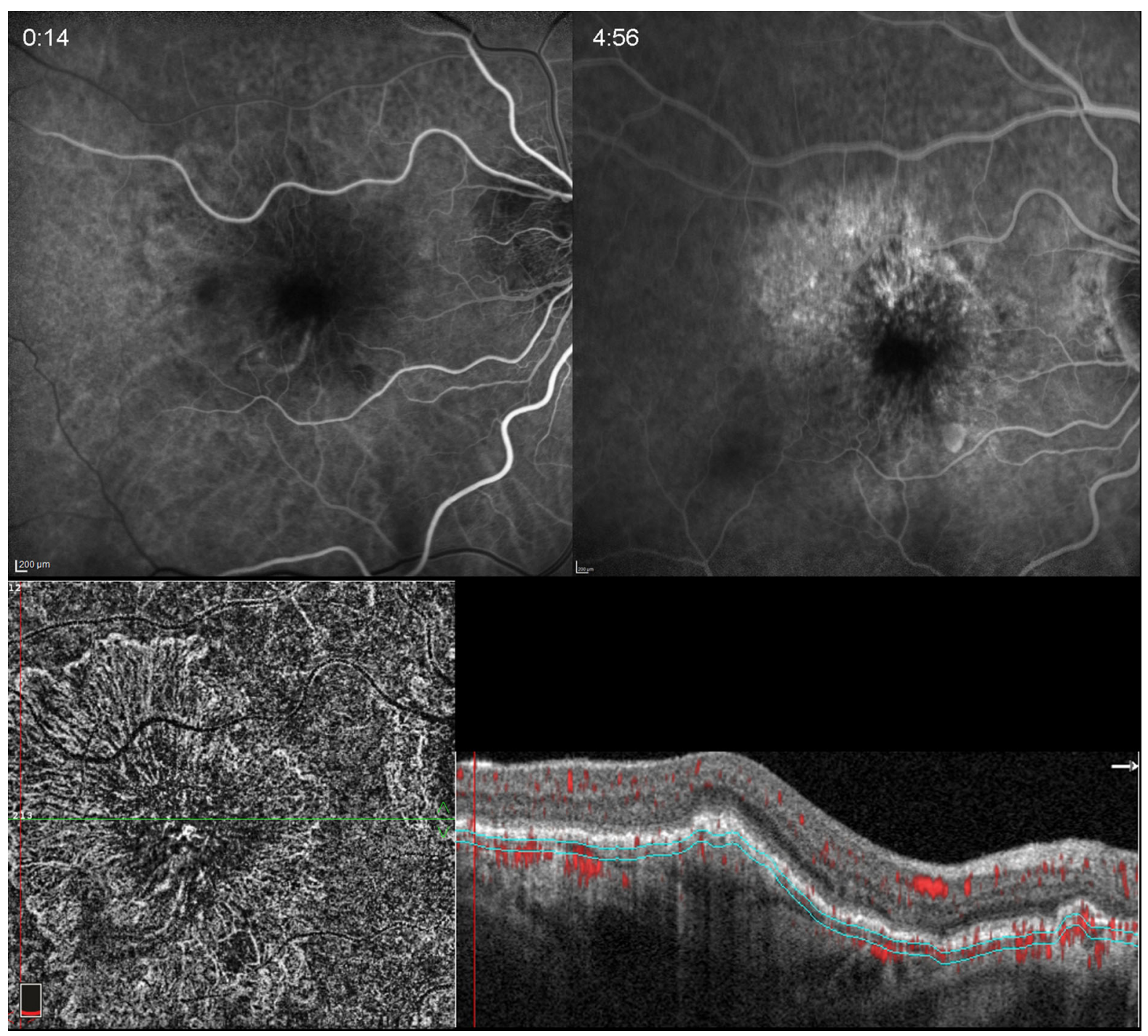

Fig. 8 Fibrovascular PED in an 89-year-old woman who had anti-VEGF treatment despite the absence of SRF or IRF in cross-sectional OCTA. Early and late phases of FA showing mild late staining. En-phase OCTA shows the

been tried in the past, with negative results [58], and therefore these cases should be observed for progression to the advanced stages of AMD.

\section{Fibrovascular/Haemorrhagic PEDs}

Fibrovascular PEDs are present in $62-80 \%$ of eyes with wet AMD [27, 59, 60]. Their natural history (similarly to wet AMD in general) is poor $[3,8,61]$. Approximately $50 \%$ of patients with
$\mathrm{CNV}$, which in this case demonstrates signs of maturity (prominent trunk vessels, pruning). This case was consid-

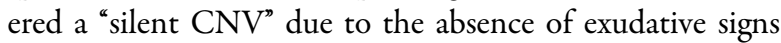
throughout follow-up

newly diagnosed PEDs will experience significant VA loss ( $>3$ lines) during the first year without any treatment [8]. The advent of antivascular endothelial factor (anti-VEGF) agents has revolutionized the treatment of wet AMD; however, fibrovascular PEDs have been associated with worse VA outcomes as well as resistance to therapy [60-62].

$\mathrm{Au}$ et al. performed a retrospective study on 88 eyes with fibrovascular PEDs that were treated with bevacizumab, ranibizumab or 
Table 1 Summary of clinical and imaging characteristics

\begin{tabular}{|c|c|c|c|}
\hline & Serous PED & Drusenoid PED & $\begin{array}{l}\text { Fibrovascular/haemorrhagic } \\
\text { PED }\end{array}$ \\
\hline Fundoscopy & $\begin{array}{l}\text { Dome-shaped elevation of the } \\
\text { RPE with sharp border }\end{array}$ & $\begin{array}{l}\text { Scalloped yellow-white elevation } \\
\text { of the RPE }\end{array}$ & $\begin{array}{l}\text { RPE elevations with irregular } \\
\text { surface }\end{array}$ \\
\hline $\begin{array}{l}\text { Fluorescein } \\
\text { angiography }\end{array}$ & $\begin{array}{l}\text { Early hyperfluorescence } \\
\text { No leakage }\end{array}$ & $\begin{array}{l}\text { Early mild hyperfluorescence } \\
\text { with late staining }\end{array}$ & $\begin{array}{l}\text { Stippled hyperfluorescence } \\
\text { with late leakage and/or } \\
\text { staining }\end{array}$ \\
\hline $\begin{array}{l}\text { Indocyanine } \\
\text { angiography }\end{array}$ & Hypofluorescence & Iso- or hypofluorescence & Hot spot or plaque \\
\hline $\begin{array}{l}\text { Fundus } \\
\text { autofluorescence }\end{array}$ & $\begin{array}{l}\text { Hyper-autofluorescent area } \\
\text { hypo-autofluorescent border }\end{array}$ & Iso- or hyperfluorescence & Hypo- or hyperfluorescence \\
\hline $\begin{array}{l}\text { Optical coherence } \\
\text { tomography }\end{array}$ & $\begin{array}{l}\text { Dome-shaped elevation of the } \\
\text { RPE with hypo-reflective } \\
\text { interior }\end{array}$ & $\begin{array}{l}\text { RPE elevations over } \\
\text { homogeneous mildly hyper- } \\
\text { reflective spaces }\end{array}$ & $\begin{array}{l}\text { Irregular elevations of the RPE } \\
\text { with inhomogeneous interior }\end{array}$ \\
\hline
\end{tabular}

PED: pigment epithelial detachment, RPE: retinal pigment epithelium

aflibercept [63]. At 1 year, there was no statistically significant VA change in either group. The mean VA change was -0.01 logmar in the bevacizumab group, 0.1 logmar in the ranibizumab group and 0.03 logmar in the aflibercept group. Overall, $18.5 \%$ of eyes demonstrated an improvement of three lines or more, $16.9 \%$ demonstrated worsening of more than three lines of vision and $64.6 \%$ eyes demonstrated stable vision. The mean reduction in PED height at 1 year was $174.53 \mu \mathrm{m}$ for aflibercept, $78.89 \mu \mathrm{m}$ for ranibizumab and $64.38 \mu \mathrm{m}$ for bevacizumab. PED height reduction was most dramatic after the first injection in all three groups. Aflibercept reduced PED height significantly more than bevacizumab at 1-month and 12-month follow-ups and ranibizumab at 1-month and 6-month follow-ups. The mean number of injections was 8.6 for bevacizumab, 10.8 for aflibercept and 10.7 for ranibizumab.

Balaskas et al. performed a retrospective study on 110 eyes with fibrovascular PEDs that were treated with ranibizumab or aflibercept [64].

At 1 year, the mean gain in VA was five letters and the average decrease in PED height was $71.5 \mu \mathrm{m}$ with a mean of 6.7 injections for aflibercept and 6.5 for ranibizumab. There was no statistically significant difference in VA gain between the two groups, but reduction in PED height was more pronounced with aflibercept. Seven eyes developed an RPE tear (4 in the ranibizumab and 3 in the aflibercept group).

Of note is the fact that in both of the abovementioned studies, there was no significant change in the linear dimensions of the PED base, suggesting that the main effect of antiVEGF agents on PEDs is an action of flattening.

Cho et al. conducted a retrospective study on 202 eyes with fibrovascular PEDs that were treated with ranibizumab or aflibercept [59]. The mean VA improved by five letters at 12 months with a mean of $4.88 \pm 1.22$ injections. The mean PED height reduction was $223 \mu \mathrm{m}$, and at 1 year PED was completely resolved in $19.3 \%$ of eyes. Twenty-two eyes (9.9\%) developed an RPE rip, 11 eyes after ranibizumab treatment $(8.4 \%)$ and 9 eyes after aflibercept treatment (12.7\%).

A post hoc analysis of the prospective randomized HARBOR study included 598 eyes with fibrovascular PEDs that were treated with two different doses $(0.5 \mathrm{mg}$ and $2 \mathrm{mg})$ of ranibizumab and with two different regimens (monthly 
and as-needed PRN) [65]. At 2 years, patients with PED gained a mean of 7.9 letters compared with 9.7 letters in patients without PED. The difference was not statistically significant $(p=0.08)$. There was also no difference in VA gains among the four ranibizumab treatment groups. The mean number of injections at 2 years was 14 in the $0.5 \mathrm{mg}$ ranibizumab PRN group, slightly more than in patients with no PED at baseline (12.5 injections). Patients in the ranibizumab $2 \mathrm{mg}$ PRN group required a similar number of injections (PED present, 11.6 injections; PED absent, 10.7 injections). The mean PED height reduction was $178.6 \mu \mathrm{m}$, and PED resolved in approximately $56 \%$ of patients at month 24. There was a trend for greater PED resolution in eyes treated with the $2 \mathrm{mg}$ dose of ranibizumab. However, patients with higher rates of PED resolution did not experience greater increases in VA, suggesting that complete resolution of the PED might not be necessary for VA gains, which seem to be related more to the resolution of IRF and SRF $[60,66]$. Furthermore, patients with complete resolution of PED were more likely to demonstrate macular atrophy at month 24 . Overall, 28 of 598 patients (4.7\%) with a PED at baseline experienced an RPE tear during the study, and the distribution of RPE tears was similar across treatment groups.

A post hoc analysis of the prospective randomized VIEW studies included 1353 eyes with fibrovascular PEDs that were treated with ranibizumab once every 4 weeks, aflibercept once every 4 weeks or aflibercept once every 8 weeks [67].

At 1 year, PED resolved in $28 \%$ of ranibizumab patients, $40 \%$ of aflibercept 4-weekly patients and $34 \%$ of aflibercept 8-weekly patients. The analysis did not report VA change in this subgroup, but the presence of PED at baseline was associated with a VA change of -1.88 letters from baseline to year 1 .

Inoue et al. conducted a prospective study on 57 eyes with PEDs associated with wet AMD treated with ranibizumab on a PRN scheme [68]. At 1 year, the mean VA change was -0.04 logmar $(<5$ letters) with a mean of six injections. RPE tear rate was $1.8 \%$.
Panos et al. conducted a similar prospective study on 62 eyes treated with PRN ranibizumab [69]. At 1 year, mean VA change was -0.11 logmar $(\sim 5$ letters $)$ with a mean 6.6 injections. Mean PED height reduction was $157.5 \mu \mathrm{m}$ and RPE tear rate was $1.6 \%$.

Chen et al. conducted a prospective study on 36 eyes with fibrovascular PED associated with either type 1 or type $3 \mathrm{CNV}$ [70]. All study eyes received 6 monthly injections of aflibercept followed by 3 bimonthly injections. An additional 3 injections were allowed if IRF and SRF were present. At baseline, $78 \%$ of eyes had type $1 \mathrm{CNV}$ and $22 \%$ type 3 . At 1 year, mean VA gain was 6.5 letters with a mean number of 10 injections. Type 3 lesions had an overall 9.2 greater letter gain compared with type 1 lesions, but the difference was not statistically significant. The mean reduction in PED height was $347 \mu \mathrm{m}(380 \mu \mathrm{m}$ in the group with type $1 \mathrm{CNV}$ and $314 \mu \mathrm{m}$ in the type $3 \mathrm{CNV}$ group). The RPE tear rate was $13.9 \%$.

Dirani et al. studied the factors influencing the treatment response of PEDs with ranibizumab and aflibercept [71]. Change in VA was influenced by baseline vision, presence or absence of SRF, and the presence of RAP. It was not associated with drug type. In particular, change in VA was negatively correlated with baseline VA; eyes with SRF at baseline OCT had a VA change that was nine letters greater than eyes with no SRF, and eyes with RAP had a VA change 10.5 letters greater than other CNV lesions. PED height reduction was associated with higher PED at baseline, lower OCT reflectivity of the PED interior and the use of aflibercept. Nevertheless, PED height reduction was not correlated with an improvement in VA [64, 68, 69], and numerous studies have also reported a lack of correlation between visual improvement and resolution of PED $[65,66,72]$. Similarly, most of the studies evaluating eyes with PEDs that were resistant to previous bevacizumab or ranibizumab treatment did not demonstrate an improvement in vision after a switch to aflibercept, despite improved anatomical outcomes [73-75].

A summary of anti-VEGF treatment outcomes in fibrovascular PEDs can be found in Table 2. 
Table 2 Summary of anti-VEGF treatment outcomes in fibrovascular PEDs

\begin{tabular}{|c|c|c|c|c|c|c|c|c|}
\hline Study & Study type & $\begin{array}{l}\text { No. } \\
\text { of } \\
\text { eyes }\end{array}$ & Drug & $\begin{array}{l}\text { Follow- } \\
\text { up } \\
\text { (year) }\end{array}$ & $\begin{array}{l}\text { Mean } \\
\text { VA } \\
\text { change }\end{array}$ & $\begin{array}{l}\text { Mean no. } \\
\text { of } \\
\text { injections }\end{array}$ & $\begin{array}{l}\text { Mean change } \\
\text { in PED height }\end{array}$ & $\begin{array}{l}\text { RPE tear } \\
\text { rate }\end{array}$ \\
\hline Au et al. & Retrospective & 88 & $\begin{array}{c}\text { Bevacizumab, } \\
\text { ranibizumab, } \\
\text { aflibercept }\end{array}$ & 1 & $\begin{array}{l}-5 \\
\text { letters }\end{array}$ & 10 & $-105.9 \mu \mathrm{m}$ & $\begin{array}{l}\text { Not } \\
\quad \text { reported }\end{array}$ \\
\hline $\begin{array}{l}\text { Balaskas } \\
\text { et al. }\end{array}$ & Retrospective & 110 & $\begin{array}{c}\text { Ranibizumab, } \\
\text { aflibercept }\end{array}$ & 1 & 5 letters & 6.6 & $-71.5 \mu \mathrm{m}$ & $6.4 \%$ \\
\hline $\begin{array}{l}\text { Cho } \\
\text { et al. }\end{array}$ & Retrospective & 202 & $\begin{array}{c}\text { Ranibizumab, } \\
\text { aflibercept }\end{array}$ & 1 & 5 letters & 4.9 & $-223 \mu \mathrm{m}$ & $9.9 \%$ \\
\hline $\begin{array}{l}\text { Sarraf } \\
\text { et al. }\end{array}$ & $\begin{array}{l}\text { Post hoc } \\
\text { analysis }\end{array}$ & 598 & Ranibizumab & 2 & $\begin{array}{l}7.9 \\
\text { letters }\end{array}$ & $\begin{array}{c}14(\mathrm{PRN} \\
0.5 \mathrm{mg} \\
\text { group) }\end{array}$ & $-178.6 \mu \mathrm{m}$ & $4.7 \%$ \\
\hline $\begin{array}{l}\text { Inoue } \\
\text { et al. }\end{array}$ & Prospective & 57 & Ranibizumab & 1 & $\begin{array}{l}<5 \\
\quad \text { letters }\end{array}$ & 6 & Not reported & $1.8 \%$ \\
\hline $\begin{array}{l}\text { Panos } \\
\text { et al. }\end{array}$ & Prospective & 62 & Ranibizumab & 1 & 5 letters & 6.6 & $-157.5 \mu \mathrm{m}$ & $1.6 \%$ \\
\hline $\begin{array}{l}\text { Chen } \\
\text { et al. }\end{array}$ & Prospective & 36 & Aflibercept & 1 & $\begin{array}{l}6.5 \\
\text { letters }\end{array}$ & 10 & $-347 \mu \mathrm{m}$ & $13.9 \%$ \\
\hline
\end{tabular}

$V E G F$ : vascular endothelial growth factor, $P E D$ : pigment epithelial detachment

\section{RPE Tears}

RPE tears were first described by Hoskin et al. as a complication of PEDs in the setting of wet AMD, and usually cause an acute decrease in VA [76]. Clinically they appear as large areas of bare choroid adjacent to an area of hyperpigmentation. On FA, an RPE tear will appear as a sharply demarcated hyperfluorescent area, corresponding to the area of absent RPE, adjacent to an area of hypofluorescence, corresponding to the area of redundant RPE. On OCT it will be visualized as a focal, sharp disruption of the RPE, with hyper-reflectivity of the underlying choroid at the area of absent RPE. FAF will reveal a hypoautofluorescent area corresponding to RPE loss.

RPE tears tend to occur at the base of the PED, near the intersection of attached and detached RPE [76]. Their pathophysiology involves tractional forces from CNV-related contraction along the RPE layer and mechanical stress at the base of the PED by increased hydrostatic pressure [77, 79].

RPE tears can occur spontaneously or after treatment including laser photocoagulation, photodynamic therapy, and anti-VEGF intravitreal injections $[8,56,77-82]$. The spontaneous tear rate in the natural history of fibrovascular PED has been reported to be between $10 \%$ and $12.5 \%[3,8,76,83]$. The rate reported after antiVEGF treatment ranges between $12 \%$ and $27 \%$ [82]. Factors associated with a high risk of RPE tear include increased PED height and a small ratio of CNV to PED size [84].

There is a degree of controversy amongst clinicians regarding treatment after the formation of RPE tears. A retrospective analysis of data from three phase III randomized clinical trials showed that patients who continued treatment after an RPE tear had better visual outcomes 
[85]. A recent prospective study demonstrated that continued anti-VEGF treatment after an RPE tear resulted in stabilization of VA over 12 months [86]. These data suggest that antiVEGF treatment after an RPE tear can be of benefit, and it should certainly be considered in patients with disease activity.

\section{CONCLUSIONS}

PED is a common feature of AMD and it is associated with different overlapping processes. It often results in loss of vision by either atrophy or CNV. Correct recognition of its various types with the aid of multimodal imaging is essential for appropriate management. Intravitreal anti-VEGF therapy is an effective treatment in the majority of eyes with fibrovascular PEDs, and similar VA outcomes have been reported with different treatment regimens. No association between anatomical and functional outcomes has been found, and therefore PED resolution is not always associated with vision improvement. Current trial data suggest that useful biomarkers for guiding treatment are the presence of IRF and SRF. When VA and PED size are stable, with no IRF or SRF, observation seems to be a reasonable approach.

\section{ACKNOWLEDGEMENTS}

Funding. No funding or sponsorship was received for this study or publication of this article.

Authorship. All named authors meet the International Committee of Medical Journal Editors (ICMJE) criteria for authorship for this article, take responsibility for the integrity of the work as a whole, and have given their approval for this version to be published.

Disclosures. Panagiotis Malamos, Petros Petrou, Ilias Georgalas, Dimitrios Papaconstantinou and Dimitrios Brouzas have nothing to declare. Michael Karampelas is a member of the journal's Editorial Board.
Compliance with Ethics Guidelines. This article is based on previously conducted studies and does not contain any studies with human participants or animals performed by any of the authors.

Open Access. This article is licensed under a Creative Commons Attribution-NonCommercial 4.0 International License, which permits any non-commercial use, sharing, adaptation, distribution and reproduction in any medium or format, as long as you give appropriate credit to the original author(s) and the source, provide a link to the Creative Commons licence, and indicate if changes were made.The images or other third party material in this article are included in the article's Creative Commons licence, unless indicated otherwise in a credit line to the material. If material is not included in the article's Creative Commons licence and your intended use is not permitted by statutory regulation or exceeds the permitted use, you will need to obtain permission directly from the copyright holder.To view a copy of this licence, visit http://creativecommons.org/licenses/by$\mathrm{nc} / 4.0 /$.

\section{REFERENCES}

1. Gass JD, Norton EW, Justice J Jr. Serous detachment of the retinal pigment epithelium. Trans Am Acad Ophthalmol Otolaryngol. 1966;70:990-1015.

2. Gass JD. Drusen and disciform macular detachment and degeneration. Trans Am Ophthalmol Soc. 1972;70:409-36.

3. Casswell AG, Kohen D, Bird AC. Retinal pigment epithelial detachments in the elderly: classification and outcome. Br J Ophthalmol. 1985;69:397-403.

4. Bird AC. Doyne Lecture: Pathogenesis of retinal pigment epithelial detachment in the elderly: the relevance of Bruch's membrane change. Eye. 1991;5:1-12.

5. Bird AC, Marshall J. Retinal pigment epithelial detachments in the elderly. Trans Ophthalmol Soc U K. 1986;105(Pt 6):674-82.

6. Poliner LS, Olk RJ, Burgess D, Gordon ME. Natural history of retinal pigment epithelial detachments in 
age related macular degeneration. Ophthalmology. 1986;93:543-51.

7. Yannuzzi LA, Sorenson J, Spaide RF, Lipson B. Idiopathic polypoidal choroidal vasculopathy (IPCV). Retina. 1990;10:1-8.

8. Pauleikoff D, Loffert D, Spital G, et al. Pigment epithelial detachment in the elderly. Clinical differentiation, natural course and pathogenetic implications. Graefes Arch Clin Exp Ophthalmol. 2002;240:533-8.

9. Sarks JP, Sarks SH, Killingsworth MC. Evolution of geographic atrophy of the retinal pigment epithelium. Eye (Lond). 1988;2:552-77.

10. Okubo A, Rosa RH Jr, Bunce CV, et al. The relationships of age changes in retinal pigment epithelium and Bruch's membrane. Investig Ophthalmol Vis Sci. 1999;40:443-9.

11. Campochiaro PA, Jerdon JA, Glaser BM. The extracellular matrix of human retinal pigment epithelial cells in vivo and its synthesis in vitro. Invest Ophthalmol Vis Sci. 1986;27:1615-21.

12. Green WR, Key SN. Senile macular degeneration: a histopathological study. Trans Am Ophthalmol Soc. 1977;75:180-254.

13. Ramrattan RS, van der Schaft TL, Mooy CM, et al. Morphometric analysis of Bruch's membrane, the choriocapillaris, and the choroid in aging. Investig Ophthalmol Vis Sci. 1994;35:2857-64.

14. Spraul CW, Lang GE, Grossniklaus HE, et al. Histologic and morphometric analysis of the choroid, Bruch's membrane, and retinal pigment epithelium in postmortem eyes with age-related macular degeneration and histologic examination of surgically excised choroidal neovascular membranes. Surv Ophthalmol. 1999;44(Suppl 1):S10-S32.

15. van der Schaft TL, Mooy CM, de Bruijn WC, et al. Histologic features of the early stages of age-related macular degeneration. A statistical analysis. Ophthalmology. 1992;99:278-86.

16. Karampelas M, Sim DA, Keane PA, et al. Evaluation of retinal pigment epithelium-Bruch's membrane complex thickness in dry age-related macular degeneration using optical coherence tomography. Br J Ophthalmol. 2013;97(10):1256-61.

17. Morre DJ, Hussain AA, Marshall J. Age-related variation in the hydraulic conductivity of Bruch's membrane. Investig Ophthalmol Vis Sci. 1995;36: 1290-7.

18. Pauleikhoff D, Harper CA, Marshall J, et al. Aging changes in Bruch's membrane. A histochemical and morphologic study. Ophthalmology. 1990;97: 171-8.

19. Bressler NM, Silva JC, Bressler SB, et al. Clinicopathologic correlation of drusen and retinal pigment epithelial abnormalities in age-related macular degeneration. Retina. 1994;14:130-42.

20. Gass JD. Serous retinal pigment epithelial detachment with a notch. A sign of occult choroidal neovascularization. Retina. 1984;4:205-20.

21. Green WR, McDonnell PJ, Yeo JH. Pathologic features of senile macular degeneration. Ophthalmology. 1985;92:615-27.

22. Gass JD. Pathogenesis of disciform detachment of the neuroepithelium. Am J Ophthalmol. 1967;63(3):1-139.

23. Fisher RF. The influence of age on some ocular basement membranes. Eye (Lond). 1987;1(Pt 2): 184-9.

24. Starita C, Hussain AA, Patmore A, Marshall J. Localization of the site of major resistance to fluid transport in Bruch's membrane. Investig Ophthalmol Vis Sci. 1997;38(3):762-7.

25. Klein R, Klein BE, Jensen SC, Meuer SM. The 5-year incidence and progression of age-related maculopathy: the Beaver Dam Eye Study. Ophthalmology. 1997;104(1):7-21.

26. Cukras C, Agron E, Klein ML, et al. Natural history of drusenoid pigment epithelial detachment in agerelated macular degeneration: Age-Related Eye Disease Study Report No. 28. Ophthalmology. 2010;117:489-99.

27. Coscas F, Coscas G, Souied E, Tick S, Soubrane G. Optical coherence tomography identification of occult choroidal neovascularization in age-related macular degeneration. Am J Ophthalmol. 2007;144(4):592-9.

28. Macular Photocoagulation Study Group. Subfoveal neovascular lesions in age-related macular degeneration. Guidelines for evaluation and treatment in the Macular Photogoaculation Study. Arch Ophthalmol. 1991;109:1242-57.

29. Young RW. Pathophysiology of age-related macular degeneration. Surv Ophthalmol. 1987;31(5): 291-306.

30. Yannuzzi LA, Flower RW, Slakter JS. Indocyanine green angiography. St. Louis: Mosby; 1997.

31. Sato T, Iida T, Hagimura N, Kishi S. Correlation of optical coherence tomography with angiography in retinal pigment epithelial detachment associated 
with age-related macular degeneration. Retina. 2004;24:910-4.

32. Yannuzzi LA, Hope-Ross M, Slakter JS, et al. Analysis of vascularized pigment epithelial detachments using indocyanine green videoangiography. Retina. 1994;14:99-113.

33. Karadimas P, Bouzas EA. Fundus autofluorescence imaging in serous and drusenoid pigment epithelial detachments associated with age-related macular degeneration. Am J Ophthalmol. 2005;140:1163-5.

34. Roth F, Holz FG. Age-related macular degeneration III-pigment epithelium detachment. In: Holz FG, Schmitz-Valckenberg S, Spaide RF, Bird AC, editors. Atlas of fundus autofluorescence imaging. Heidelberg: Springer; 2007. p. 165-177.

35. Gass JDM. Stereoscopic atlas of macular disease: diagnosis and management. St. Louis: Mosby; 1997. p. 24-26.

36. Arnold JJ, Quaranta M, Soubrane G, et al. Indocyanine green angiography of drusen. Am J Ophthalmol. 1997;124:344-56.

37. Flower RW, Csaky KG, Murphy RP. Disparity between fundus camera and scanning laser ophthalmoscope indocyanine green imaging of retinal pigment epithelium detachments. Retina. 1998;18: 260-8.

38. Schmitz-Valckenberg S, Fleckenstein M, Scholl HP, Holz FG. Fundus autofluorescence and progression of age-related macular degeneration. Surv Ophthalmol. 2009;54:96-117.

39. Sikorski BL, Bukowska D, Kaluzny JJ, Szkulmowski M, Kowalczyk A, Wojtkowski M. Drusen with accompanying fluid underneath the sensory retina. Ophthalmology. 2011;118(1):82-92.

40. Gass JD. Biomicroscopic and histopathologic considerations regarding the feasibility of surgical excision of subfoveal neovascular membranes. Am J Ophthalmol. 1994;118:285-98.

41. Macular Photocoagulation Study Group. Subfoveal neovascular lesions in age-related macular degeneration. Guidelines for evaluation and treatment in the macular photocoagulation study. Arch Ophthalmol. 1991;109:1242-57.

42. Camacho N, Barteselli G, Nezgoda JT, et al. Significance of the hyperautofluorescent ring associated with choroidal neovascularisation in eyes undergoing anti-VEGF therapy for wet age-related macular degeneration. $\mathrm{Br} \mathrm{J}$ Ophthalmol. 2015;99(9): 1277-83.
43. Batioglu F, Demirel S, Ozmert E, Oguz YG, Ozyol P. Autofluorescence patterns as a predictive factor for neovascularization. Optom Vis Sci. 2014;91(8): 950-5.

44. Spaide RF. Enhanced depth imaging optical coherence tomography of retinal pigment epithelial detachment in age-related macular degeneration. Am J Ophthalmol. 2009;147:644-52.

45. Jia Y, Bailey ST, Wilson DJ, et al. Quantitative optical coherence tomography angiography of choroidal neovascularization in age-related macular degeneration. Ophthalmology. 2014;121:1435-44.

46. Veronese C, Maiolo C, Morara M, Armstrong GW, Ciardella AP. Optical coherence tomography angiography to assess pigment epithelial detachment. Retina. 2016;36(3):645-50.

47. Tan ACS, Freund KB, Balaratnasingam C, Simhaee D, Yannuzzi LA. Imaging of pigment epithelial detachments with optical coherence tomography angiography. Retina. 2018;38(9):1759-69.

48. Laatikainen L, Hoffren M. Long-term follow-up study of nonsenile detachment of the retinal pigment epithelium. Eur J Ophthalmol. 1991;1:79-84.

49. Guyer DR, Yannuzzi LA, Slakter JS, et al. Digital indocyaninegreen videoangiography of occult choroidal neovascularization. Ophthalmology. 1994;101:1727-35.

50. Lommatzsch A, Heimes B, Gutfleisch M, et al. Serous pigment epithelial detachment in age-related macular degeneration: comparison of different treatments. Eye (Lond). 2009;23:2163-8.

51. Elman MJ, Fine SL, Murphy RP, et al. The natural history of serous retinal pigment epithelium detachment in patients with age-related macular degeneration. Ophthalmology. 1986;93:224-30.

52. Meredith TA, Braley RE, Aaberg TM. Natural history of serous detachments of the retinal pigment epithelium. Am J Ophthalmol. 1979;88:643-51.

53. Braunstein RA, Gass JD. Serous detachments of the retinal pigment epithelium in patients with senile macular disease. Am J Ophthalmol. 1979;88: 652-60.

54. The Moorfields Macular Study Group. Retinal pigment epithelial detachments in the elderly: a controlled trial of argon laser photocoagulation. $\mathrm{Br} \mathrm{J}$ Ophthalmol. 1982;66:1-16.

55. Tvenning AO, Hedels C, Krohn J, Austeng D. Treatment of large avascular retinal pigment epithelium detachments in age-related macular degeneration with aflibercept, photodynamic 
therapy, and triamcinolone acetonide. Clin Ophthalmol. 2019;13:233-41.

56. Hartnett ME, Weiter JJ, Garsd A, Jalkh AE. Classification of retinal pigment epithelial detachments associated with drusen. Graefes Arch Clin Exp Ophthalmol. 1992;230(1):11-9.

57. Roquet W, Roudot-Thoraval F, Coscas G, Soubrane G. Clinical features of drusenoid pigment epithelial detachment in age related macular degeneration. $\mathrm{Br}$ J Ophthalmol. 2004;88(5):638-42.

58. Friberg TR, Brennen PM, Freeman WR, Musch DC, Group PS. Prophylactic treatment of age-related macular degeneration report number 2: 810-nm laser to eyes with drusen: bilaterally eligible patients. Ophthalmic Surg Lasers Imaging. 2009;40(6):530-8.

59. Cho HJ, Kim KM, Kim HS, Lee DW, Kim CG, Kim JW. Response of pigment epithelial detachment to anti-vascular endothelial growth factor treatment in age-related macular degeneration. Am J Ophthalmol. 2016;166:112-9.

60. Schmidt-Erfurth U, Waldstein SM, Deak GG, Kundi M, Simader C. Pigment epithelial detachment followed by retinal cystoid degeneration leads to vision loss in treatment of neovascular age-related macular degeneration. Ophthalmology. 2015;122: 822-32.

61. Hoerster R, Muether PS, Sitnilska V, Kirchhof B, Fauser S. Fibrovascular pigment epithelial detachment is a risk factor for long-term visual decay in neovascular age-related macular degeneration. Retina. 2014;34(9):1767-73.

62. Mariani A, Deli A, Ambresin A, Mantel I. Characteristics of eyes with secondary loss of VA receiving variable dosing ranibizumab for neovascular agerelated macular degeneration. Graefes Arch Clin Exp Ophthalmol. 2011;249:1635-42.

63. Au A, Parikh VS, Singh RP, et al. Comparison of anti-VEGF therapies on fibrovascular pigment epithelial detachments in age-related macular degeneration. Br J Ophthalmol. 2017;101(7):970-5.

64. Balaskas K, Karampelas M, Horani M, Hotu O, Keane P, Aslam T. Quantitative analysis of pigment epithelial detachment response to different antivascular endothelial growth factor agents in wet age-related macular degeneration. Retina. 2017;37(7):1297-304.

65. Sarraf D, London NJ, Khurana RN, et al. Ranibizumab treatment for pigment epithelial detachment secondary to neovascular age-related macular degeneration: post hoc analysis of the HARBOR study. Ophthalmology. 2016;123(10):2213-24.
66. Chen E, Kaiser RS, Vander JF. Intravitreal bevacizumab for refractory pigment epithelial detachment with occult choroidal neovascularization in age-related macular degeneration. Retina. 2007;7(4):445-50.

67. Waldstein SM, Simader C, Staurenghi G, et al. Morphology and visual acuity in aflibercept and ranibizumab therapy for neovascular age-related macular degeneration in the VIEW trials. Ophthalmology. 2016;123:1521-9.

68. Inoue $\mathrm{M}$, Arakawa $\mathrm{A}$, Yamane $\mathrm{S}$, Kadonosono $\mathrm{K}$. Variable response of vascularized pigment epithelial detachments to ranibizumab based on lesion subtypes, including polypoidal choroidal vasculopathy. Retina. 2013;33:990-7.

69. Panos GD, Gatzioufas Z, Petropoulos IK, Dardabounis D, Thumann G, Hafezi F. Effect of ranibizumab on serous and vascular pigment epithelial detachments associated with exudative age-related macular degeneration. Drug Des Dev Ther. 2013;10(7):565-9.

70. Chen X, Al-Sheikh M, Chan CK, et al. Type 1 versus type 3 neovascularization in pigment epithelial detachments associated with age-related macular degeneration after anti-vascular endothelial growth factor therapy: a prospective study. Retina. 2016;36(S1):S50-S64.

71. Dirani A, Ambresin A, Marchionno L, Decugis D, Mantel I. Factors influencing the treatment response of pigment epithelium detachment in agerelated macular degeneration. Am J Ophthalmol. 2015;160(4):732-8.

72. Ach T, Hoeh AE, Ruppenstein M, Kretz FT, Dithmar $S$. Intravitreal bevacizumab in vascular pigment epithelium detachment as a result of subfoveal occult choroidal neovascularization in age-related macular degeneration. Retina. 2010;30(9):1420-5.

73. Kanesa-Thasan A, Grewal DS, Gill MK, Lyon AT, Mirza RG. Quantification of change in pigment epithelial detachment volume and morphology after transition to intravitreal aflibercept in eyes with recalcitrant neovascular AMD: 18-month results. Ophthalmic Surg Lasers Imaging Retina. 2015;46(6):638-41.

74. de Massougnes S, Dirani A, Ambresin A, Decugis D, Marchionno L, Mantel I. Pigment epithelial detachment response to aflibercept in neovascular age-related macular degeneration refractory to ranibizumab: time course and drug effects. Retina. 2016;36(5):881-8.

75. Spooner K, Hong T, Wijeyakumar W, Chang AA. Switching to aflibercept among patients with treatment-resistant neovascular age-related macular 
degeneration: a systematic review with meta-analysis. Clin Ophthalmol. 2017;6(11):161-77.

76. Hoskin A, Bird AC, Sehmi K. Tears of detached retinal pigment epithelium. $\mathrm{Br} \mathrm{J}$ Ophthalmol. 1981;65:417-22.

77. Gass JD. Pathogenesis of tears of the retinal pigment epithelium. Br J Ophthalmol. 1984;68(8): 513-9.

78. Cantrill HL, Ramsay RC, Knobloch WH. Rips in the pigment epithelium. Arch Ophthalmol. 1983;101(7):1074-9.

79. Gelisken F, Inhoffen W, Partsch M, Schneider U, Kreissig I. Retinal pigment epithelial tear after photodynamic therapy for choroidal neovascularization. Am J Ophthalmol. 2001;131(4):518-20.

80. Dhalla MS, Blinder KJ, Tewari A, Hariprasad SM, Apte RS. Retinal pigment epithelial tear following intravitreal pegaptanib sodium. Am J Ophthalmol. 2006;141(4):752-4.

81. Chan CK, Meyer CH, Gross JG, et al. Retinal pigment epithelial tears after intravitreal bevacizumab injection for neovascular age-related macular degeneration. Retina. 2007;27:541-51.

82. Doguizi S, Ozdek S. Pigment epithelial tears associated with anti-VEGF therapy: incidence, longterm visual outcome, and relationship with pigment epithelial detachment in age-related macular degeneration. Retina. 2014;34(6):1156-62.

83. Chuang EL, Bird AC. Repair after tears of the retinal pigment epithelium. Eye. 1988;2(Pt 1):106-13.

84. Chiang A, Chang LK, Yu F, Sarraf D. Predictors of anti-VEGF-associated retinal pigment epithelial tear using FA and OCT analysis. Retina. 2008;28:1265-9.

85. Cunningham ET Jr, Feiner L, Chung C, Tuomi L, Ehrlich JS. Incidence of retinal pigment epithelial tears after intravitreal ranibizumab injection for neovascular age-related macular degeneration. Ophthalmology. 2011;118:2447-522.

86. Larsen PP, Oishi A, Bedar M, et al. Ranibizumab in pigment epithelial tears secondary to age-related macular degeneration: a prospective study. Retina. 2019;39(12):2369-77. 